\title{
Encoding of auditory stimuli in recognition memory tasks*
}

\author{
MARGARET CLARK, SHARON STAMM, RICHARD SUSSMAN, and STEVEN WEITZ \\ Franklin and Marshall College, Lancaster, Pennsylvania 17604
}

\begin{abstract}
A tape of 13 relatively labelable and 13 nonlabelable sounds was presented to 13 Ss. Later a second tape containing these same 26 sounds plus 17 new labelable sounds and 17 new nonlabelable sounds was presented to the same Ss. They were asked to indicate when they recognized a sound from the first tape. Ss were able to recognize a significantly greater number of the original labelable sounds than of the original nonlabelable sounds. These results seem to indicate that a dual coding process operates for sounds as well as for visual pictures and objects.
\end{abstract}

It has been found that recall of nonverbal visual stimuli (i.e., objects or pictures) is superior to recall of verbal stimuli (i.e., words). This result has been found in a variety of recall tasks, including free recall (Lieberman \& Culpepper, 1965; Paivio, Rogers, \& Smythe, 1968), serial recall (Paivio \& Csapo, 1969), and recognition memory tasks (Jenkins, Neale, \& Deno, 1967; Dallet \& Wilcox, 1968). Paivio (1971) has postulated a dual coding process to account for these findings. According to Paivio, the superior recall of pictures or objects as compared to their verbal equivalents can be attributed to the coding and storage of nonlinguistic and a linguistic representation of the picture or object, while there is only storage of a lingu: tic representation of its verbal equivalent.

In an attempt to test for the possible existence of a similar dual coding process operating in the memory for sounds, Kicey (1970) compared free recall of sounds and their noun equivalents. Her results did not show superior recall of sounds, but she attributed this failure to a dif iculty in attaching verbal labels to the sound stimuli. Using a connparable paradigm and comparable criterion for sound labelability, Philipchalk and Rowe (1971) fourd similar results for free recall. Since the sounds utilized in both these studies were not $100 \%$ labelable, the possibility of a dual coding process operating in the auditory mode remained open.

A different approach toward testing for the possible existence of such a dual coding process for sounds was taken in the present study. A recognition memory task was used to compare recognition of relatively labelable sounds to recognition of relatively nonlabelable sounds. A recognition memory task was used rather than a free recall task, since it was felt that the transfer from auditory stimulus to a motor-visual response might have obscured the effect of dual coding in earlier studies.

\section{METHOD}

\section{Subjects}

Thirteen introductory psychology students at Franklin and Marshall College were used as Ss. Both males and females participated. No $S$ had any hearing difficulties.

*Sponsored by Eugene B. Wist, who takes full editorial responsibility for it.

\section{Apparatus}

The apparatus was set up in a master control room and three "social isolation booths." Each booth prevented Ss from seeing one another and adequately eliminated extraneous sounds. In each booth was a chair and a table upon which the following items could be found: a set of headphones (Lafayette SP-22), an intercom substation (Talk-a-Phone K-LR-3M), and a relay light operated by a button and used as a signal between the $S$ and the E. The control room from which the Es operated contained the following items: an intercom master station (Talk-a-Phone K-ML-5), three master lights corresponding to each S's button, and the resets of the signal lights. A tape deck (Panasonic Cassette, Model RS-26145) drove the S's and the E's headphones. A voice-activated relay, started by the recorded sounds, activated three Hunter Klockounters (one for each S), which were stopped when the $S$ released a telegraph key in his booth. Materials used included two stimulus tapes and an instruction tape. One tape consisted of 13 "labelable" sounds (i.e., sounds of a rooster, saw, car, water, laughter, toothbrush, snoring, dog, baby, telephone, knocking, horn, coughing) and 13 "nonlabelable" sounds (i.e., lathe, applause, frog, waterfall, vacuum, tearing, spray, calculator, lawn mower, linotype, factory). All sounds were taken from "Sound Effects Records" (Volumes 1-13) manufactured by the Electra Corporation, 15 Columbus Circle, New York, New York. These sounds were selected on the basis of a pilot study in which the "labelable" sounds were assigned a label by $93.3 \%-100 \%$ of 15 Ss. The "nonlabelable" sounds were labeled by $13.3 \%-78.6 \%$ of these same Ss. All sounds were randomly ordered on the tape. Each sound lasted for $3 \mathrm{sec}$, and there was a 5 -sec interitem interval. The second stimulus tape consisted of 60 sounds, including the 26 sounds on the first tape and 34 additional sounds. These consisted of 17 new "labelable" and 17 new "nonlabelable" sounds chosen using the same criterion as used for the stimuli on the first tape. Again, each sound lasted for $3 \mathrm{sec}$ and the sounds were randomly ordered on the tape but there was a 10 -sec interitem interval. Printed instructions, which were identical to the taped ones, and two sheets of random numbers were available to each $S$.

\section{Procedure}

The Ss were escorted three at a time to the social isolation booths. They were seated and asked to put on their earphones. Then an E started the following instruction tape: "You will be listening to a list of everyday sounds. You will hear this list two times. The first time you hear the sounds we would like you to relax, listen to the sounds as you would if you were hearing them in everyday life. Later, you will receive instructions on how to listen to the second presentation of sounds." The Ss then heard the first stimulus tape of 22 randomly ordered "labelable" sounds. At the end of this tape, one $E$ entered each booth and handed the $S$ two sheets of random numbers and a pencil. The $S$ 
was requested to cross out any two consecutive ascending integers. The Ss were left alone, and they crossed out numbers for $5 \mathrm{~min}$. After this time had elapsed, the E returned, picked up the sheets of numbers and the pencil, and handed the $S$ a typed set of the following instructions: "In a moment you will hear sixty sounds. Some of these will be those you have just heard. Others will be entirely new to you. If you have heard the sound before, lift your finger from the key in front of you. Then immediately press your red button. When your red light goes off then put your finger back on the key. If a sound is new to you do not take your finger from the key. Do not guess wildly-a score will be determined by subtracting wrong answers from right ones."

The $\mathrm{E}$ in each booth with the $\mathrm{S}$ would then ask him to press his finger down on the telegraph key. He asked the $S$ to pretend that, when he said GO, he had heard a sound which he recognized from the original stimulus tape, to lift his finger from the key, and then to replace it on the key when the indicator light in front of him went off. Each $S$ repeated this procedure 10 times (or more for some Ss). The three Ss then heard the stimulus tape of 60 sounds and lifted their fingers from the key when they recognized a sound. Meanwhile, three Es were recording whether or not a sound was recognized and the latencies of recognized sounds. A fourth E reset each S's signal, light which lit every time a sound was recognized. This $E$ also stopped all three timers after 5 or $6 \mathrm{sec}$ had elapsed following the onset of a sound, which enabled the other Es to reset their timers. This procedure cleared the way for the next sound, presented $10 \mathrm{sec}$ later. After all 60 sounds had been played to the Ss, they were debriefed, thanked, and allowed to leave.

\section{RESULTS}

The mean number of correct identifications of "labelable" sounds was $8.85(\mathrm{SD}=1.56)$, while the mean number of correct recognition of "nonlabelable" sounds was $4.92(\mathrm{SD}=2.43)$. An analysis of variance for repeated measures was used to compare the numbers of correct recognitions of "labelable" sounds with the number of correct recognitions of "nonlabelable" sounds. The difference between recognition scores for the two types of sounds was highly significant, $\mathrm{F}=$ $25.85, \mathrm{p}<.001$. The mean latency to correct recognition was $2.247 \mathrm{sec}$ for labelable sounds and $1.846 \mathrm{sec}$ for "nonlabelable" sounds. An analysis of variance for repeated measures revealed that this difference approached, but did not reach, significance, $\mathrm{F}$ $=3.50, \mathrm{p}<.10$.

A Pearson product-moment correlation was performed to determine whether Ss who had a high number of correct recognitions also had a high number of false alarms (i.e., recognitions of sounds not in the original stimulus tape). This was a test for artificial inflation of recognition scores due to a large number of recognition responses. No significant correlation was found $(\mathrm{r}=.13)$.

Finally, a Kendall rank-order correlation was utilized to determine whether a relationship existed between the degree of labelability (of "nonlabelable" sounds) and the ease of recognition for those particular sounds. A nonsignificant tau of 21 was obtained. This analysis was not performed for the labelable sounds since there was little variation in labelability within this group of sounds.

\section{DISCUSSION}

The most important finding was that labelable sounds were correctly identified significantly more often than were nonlabelable sounds. This is what had been predicted and supports our contention that Paivio's (1971) dual coding hypothesis may be taken to apply to sounds as well as to visual images. There is a linguistic as well as a nonlinguistic representation of nonlabelable sounds which is available for coding. The fact that there was no significant correlation between the number of correct and false recognitions made by each $\mathrm{S}$ shows that the high recognition scores were not obtained because of a high false alarm rate.

It is not possible to draw a conclusion ce ncerning the failure to find a significant difference in latencies tc recognize labelable vs nonlabelable sounds on the basis of the present data. Perhaps there is no difference in retrieval time necessary for auditory traces plus words vs auditory traces alone. In other words, retrieval of dually coded information may be parallel. On the other hand, there may be a difference in time necessary to retrieve a sound plus a word vs a sound alone, but this difference in required time might be small in relation to the measurement error for reaction times in this study.

Finally, there remains the question of the role that "familiarity" plays in this process. It is possible that "labelable" sounds or visual objects are more familiar than "nonlabelable" sounds or written words and therefore are easier to recall. Further studies in which familiarity and labelability are disassociated are necessary to resolve this question.

\section{REFERENCES}

Dallett, K., \& Wilcox, S. G. Remembering pictures versus remembering descriptions. Psychonomic Science, 1968, 11, 139-140.

Jenkins, J. R., Neale, D. C., \& Deno, S. L. Differential memory for picture and word stimuli. Journal of Educational Psychology, 967, 58, 303-307.

Kicey, C. A comparison of free recall of "auditory pictures" and their noun equivalents. Unpublished paper, Franklin and Marshall College, 1970.

Lieberman, L. R., \& Culpepper, J. T. Words versus objects: A comparison of free verbal recall. Psychological R eports, 1965, 17, 983-988

Miller, J. D., \& Tanis, D. C. Recognition memory for common sounds. Psychonomic Science, 1971, 23, 307-308.

Paivio, A. Imagery and verbal processes. New York: Holt, Rinehart \& Winston, 1971.

Paivio, A., \& Csaop, K. Concrete image and verbal memory codes. Journal of Experimental Psychology, 1969, 80, 279-285.

Paivio, A., Rogers, T. B., \& Smythe, P. C. Why are pictures easier to recall than words? Psychonomic Science, 1968, 11, 137-138.

(Received for publication November 16, 1973.) 